\title{
Research on Urban Waterfront Landscape Design Based on Ecological Urbanism
}

\author{
Xukun $\mathrm{Wu}^{1, *}$ \\ ${ }^{1}$ School of Art and Design of Wanjiang University of Technology, Ma'anshan, 243000, China
}

\begin{abstract}
In the overall urban environment the urban waterfront landscape area plays a dual function of landscape and culture, and is an important incubator for the natural ecology of the city. Therefore, the shaping of the locality of the urban waterfront space is not only to create a beautiful city card, but also to improve the ecology of the city and the inevitable requirements of waterfront landscape construction. This paper first analyses the basic theory of urban waterfront landscape, and then conducts an in-depth study on the principles of urban waterfront landscape design under the ecological design concept. Solutions are proposed for the current problems of urban waterfront landscape design, and feasible landscape design methods are proposed in conjunction with the concept of ecological urbanism. The urban landscape is seen as a resource, guided by the theories of ecology and landscape ecology, and the principles of the ecological design concept, with a view to establishing a harmonious and symbiotic relationship between the environment, the landscape and people, and meeting people's needs and spiritual aspirations.
\end{abstract}

\section{Introduction}

Urban waterfronts with unique geographical advantages have long been favoured, and most of the most valuable waterfronts in any country in the world are dependent on natural bodies of water [1]. In the process of urban planning and design, particular attention has been paid to the development and construction of waterfront areas. The urban waterfront is an important component of a city's public open space and an important showcase of the city's landscape [2]. A good and beautiful urban waterfront landscape plays an important role in enhancing the appearance of the city and increasing its external attractiveness. However, in recent years, as a doubleedged sword, the regionalisation of waterfront landscapes in cities has led to the modernisation and development of urban economies, while at the same time being damaged by man, leading to a decline in the quality of the urban ecological environment [3]. Therefore, this paper addresses the current problems, combines multidisciplinary knowledge, takes ecological urbanism as a theoretical guide, adheres to the concept of sustainable development, and conducts research on the design of waterfront urban landscapes, which provides practical implications for the design of relevant waterfront spaces in the future.

\section{Ecological Urbanism and Waterfront Landscape Theory Analysis}

\subsection{Eco-urbanism}

The founder of the theory of 'ecological urbanism', Mohsen Mostafavi, did not give a precise definition of the concept. It is not exactly defined, but is understood in the light of other books on the subject [4]. The emphasis is on the interpretation of ecological issues in terms of human subjectivity, social relations and the surrounding environment, i.e. eco-urbanism focuses on the use of fewer resources to build cities rather than just how to plan them.

Eco-urbanism sees the city as a system, an urban ecosystem, and seeks to create a harmonious, efficient, green, urban-age human habitat in all its social, economic, cultural, planning and technological aspects. In the face of the built-up modern city, eco-urbanism uses 'design' to transform the surrounding ecological environment. Figure 1 shows two typical eco-urbanist landscapes in China.

\subsection{Urban Waterfront Landscape}

The urban waterfront is the collective name for a number of special areas in the city where water and land are connected, and is usually divided into riverfront, lakeside and waterfront categories according to the size and type of water body [5]. The former mainly includes natural topography and water bodies, while the latter mainly includes artificially constructed recreational paths, nodes,

\footnotetext{
*Corresponding author: 1931010013@ahnu.edu.cn
} 
markers, barge boundaries, public areas and so on. The urban waterfront landscape is a kind of landscape, mostly distributed along the water in a linear or ribbon shape, which has unique natural characteristics from the morphological point of view, and it is also an important ecological corridor in the city.

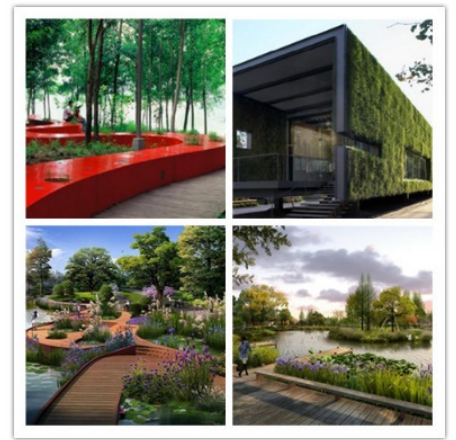

Fig. 1. Domestic ecological landscape design diagram

According to its substrate can be further subdivided into waterfront land landscape, waterfront water landscape and waterfront land and water interface barge landscape. The land landscape is the transitional interface between the waterfront landscape and the city, and is the main activity space for people's leisure and recreation; the water landscape is a special material entity of the urban space, with a strong shapeability of the water body, which can provide a variety of special water activity space; the barge landscape is a special interface of the waterfront area, and is also an important ecological boundary, and has an important flood control function [6]. In short, each sub-category has its own landscape qualities due to its different substrates, creating a diverse and comfortable public activity space for people.

\section{Principles of urban waterfront landscape design from an ecological design perspective}

The concept of ecological design refers to the use of ecological principles for theoretical guidance, analysis of various material information and the prevention or reduction of the impact of urban development on 'nature' through means that are not limited to 'science', in order to ultimately achieve 'sustainability' for people and the environment. "Sustainable'. This design philosophy emphasises the use of scientific and technological knowledge, in-depth study of the relationship between humans and nature, rational analysis of the environmental problems caused by human socio-economic activities, and a re-examination of the exact position of humans in the natural world, in order to seek a sensible and scientific approach to development that is in harmony with nature [7].

\subsection{Principles of urban waterfront landscape design from an ecological design perspective}

The urban landscape has moved from a consciously formdriven model at the beginning of the 20th century to a spontaneous growth pattern based largely on quantitative procedures and normative standards. In this process, traditional landscape identity can collide brutally and inescapably with issues of land value, property development, productivity and mobility, resulting in a confusing, sluggish and visually unpleasant urban landscape [8]. The formation of the urban waterfront landscape is a complex movement of intertwined time periods and internal systems according to geographical differences, a long and evolving continuum, a convergence of countless historical moments compressed into a particular space. On these premises, landscape design needs to unravel the 'genetic code' hidden in the process of change, avoiding an environment isolated from the outside world due to the lack of a holistic design concept and the crude collage of heterogeneous elements.

The urban waterfront landscape is characterised by its human orientation and its purpose is to serve people, and its built environment should meet the needs of people and give them a pleasant spatial experience. Therefore, with the principle of health and comfort as the main objective, the aim is to create a recognisable and pleasant place, mainly through the use of native plants and local construction materials, the creation of a pollution-free local climate, the design of pedestrian outdoor space, soundscape design and traffic noise prevention [9].

The local character of the landscape is reflected in both the artificial landscape and the urban human ecosystem. When selecting plants for configuration, the growth and development characteristics of the plants themselves and their connection with the surrounding environment need to be taken into consideration. The use of local construction materials not only reduces the time and cost of manual conservation and management, but also promotes the conservation and renewal of the environment itself; the use of local construction materials saves the non-renewable energy used in the transportation of off-site materials and the resulting increase in construction costs, and greatly reduces damage to the offsite ecological environment. More importantly, the use of local materials brings a strong sense of place, belonging and identity, and reflects the simplicity and richness of the local traditional style; the spatial existence of the urban human ecosystem depends not only on the continuity of the geographical environment, but also on the commonality and continuity of technical and economic activities, social and cultural activities and folkloric characteristics, as well as on the irreducibility of the human environment due to its differences.

\subsection{Maintaining the original physical geography}

The urban waterfront landscape is a complex of interacting patches, corridors and substrates mosaic in a certain pattern of spatially heterogeneous units in the area. A patch is the most visible form of landscape structure, a non-linear surface area that differs from the surrounding 
area. At the regional scale, large ecological patches are the only areas that have a complete landscape structure and retain rich vegetation, sufficient corridors to protect water bodies, maintain biodiversity within the patch, and provide habitat for vertebrates, as shown in Figure 2. The different types of patch can be spatially random, homogeneous or clustered, with the patch form being influenced by local topography and climatic conditions, slope and wind relationships; corridors have a more distinct spatial character within the land complex, partly linking different elements of the landscape and partly separating some other different elements of the landscape to form a whole. Its structure and function are closely related to the degree of connectivity within the landscape area, and it is a narrow-shaped strip of space, mainly including vegetation corridors, river and valley corridors and transport corridors, etc. The formation of corridors is influenced by topography, climate and vegetation distribution; the spatial form of the matrix depends on the distribution of patches and corridors within it, and its characteristics largely govern the direction of development and the choice of management measures for the whole area.

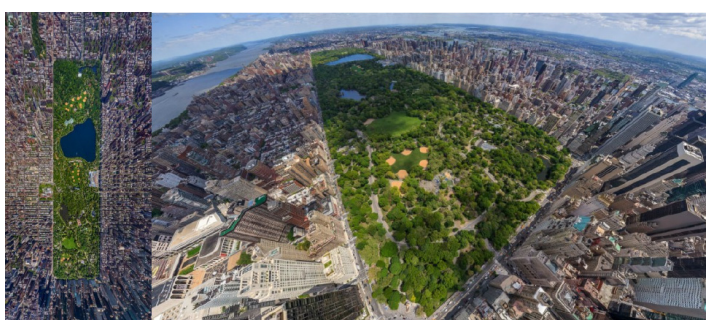

Fig. 2. Large ecological patches in New York's Central Park

\subsection{Effective use of material resources}

Under the guidance of the ecological concept, the selection and design of material resources in the urban waterfront landscape includes the transformation of the original structures of the base and the recycling and utilisation of waste materials. This is achieved through the '4Rs' principle, i.e. Reduce, Use, Recycle and Renew.

The renovation of the original structures of the base consists of two main aspects: firstly, the conservation and use of historical buildings, i.e. the use of the flexibility of the internal space to make one or more changes to the use function of the building system during its physical life, while preserving the architectural style; secondly, the use of abandoned industrial sites of contemporary significance, i.e. the renovation of some well-preserved and still good quality structures to new use requirements based on their original condition.

The design of urban waterfront landscapes is achieved through the transformation of the original structures of the site by both preserving the original appearance and replacing the old with the new. Retaining the original appearance means highlighting the historical sculptural status of the structure by means of appropriate maintenance such as repairing its appearance, emphasising the visual symbolism and creating a landmark landscape that evokes memories of the past, as shown in Figure 3. The replacement of the old with the new refers to the partial addition or complete renewal of the material or form of the structure, in order to produce a new style of appearance and to give a new functional interpretation, ultimately interspersing history with the present in a natural way, giving the landscape a sense of dialogue between time and space.

Discarded construction materials can be restored and then re-displayed to present a unique landscape with historical significance or treated as part of a new material language so that they can be fully integrated into the site, as shown in Figure 4.

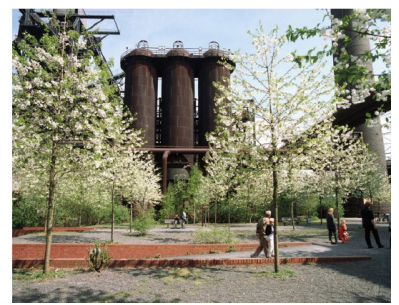

Fig. 3. Renovation of old buildings

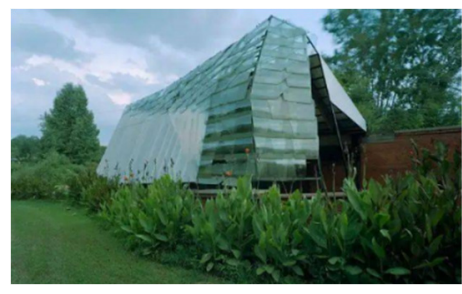

Fig. 4. Reuse of waste construction materials

\section{Urban waterfront landscape design strategies based on ecological urbanism}

\subsection{Overall planning and integration strategy}

The urban waterfront is an important part of the city and is also a more ecologically sensitive area. The two landscape analysis methods of landscape urbanism horizontal analysis and vertical analysis. In the landscape planning and design of urban waterfronts, an ecological bottom line should first be drawn for the construction of the waterfront.

The horizontal pattern formed by the horizontal analysis method is to link the ecological core, buffer zone and other areas in the urban waterfront through three landscape structural units: patch, corridor and base system, forming a horizontal ecological network system of the waterfront, as shown in Figure 5. The ecological network of the waterfront is improved and the internal landscape is designed to ensure the sustainability of the waterfront. 


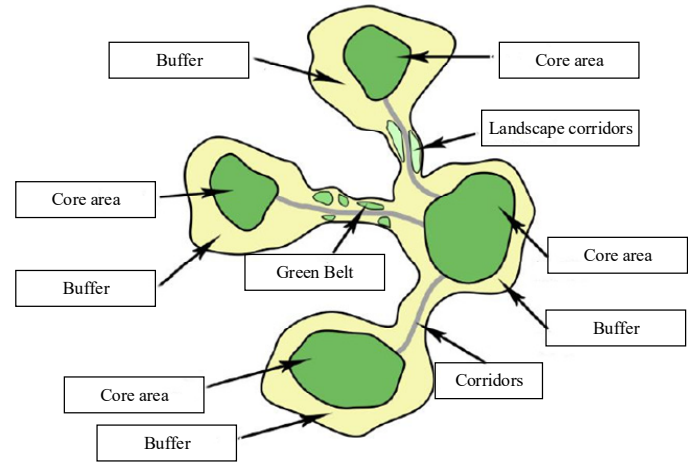

Fig. 5. Schematic diagram of the ecological network

The vertical analysis method is applied to the urban waterfront by integrating the topography, soil, hydrology, biology and human activities, and by superimposing the corresponding weighting ratios to obtain a comprehensive evaluation map of the suitability of the waterfront for land use, with the degree of suitability of each area of the waterfront for conservation and development derived from the shades of colour.

In the construction of the urban waterfront, a comprehensive vertical and horizontal pattern is superimposed to arrive at the ecological pattern of the urban waterfront. From the perspective of landscape urbanism, this ecological pattern is the ecological bottom line for the development of the area.

\subsection{Green Infrastructure Building Strategy}

The main types of sponge city technology systems used in urban waterfronts are permeable paving, ecological interceptor ditches, rain gardens (ecological purification and detention ponds), waterfront plant restoration areas and green roofs.

Permeable paving means that rainwater can percolate through the paving surface to the surface soil layer of the paving material, the main advantage is that it is widely used and easy to construct, rainwater permeable paving after the infiltration of groundwater has a certain complementary effect, the disadvantage is that it is easy to freeze and crack.

Ecological interceptors are shallow surface ditches planted with herbaceous plants, which have an inverted trapezoidal cross-section and can be used to channel runoff rainwater.

Flood control is one of the most important functions of urban waterfront infrastructure, and many mega-cities such as Shanghai, China line up to collect and treat it.

\subsection{Regional culture building strategies}

The existing legacy material carriers of the urban waterfront, such as buildings, docks and piers, should be used in a rational way, and their functions should be reshaped through restoration and renovation to retain the original historical imprint of the site. In terms of function, this can be a continuation of the original function, or it can be replaced with a public activity space related to the functions around the site. The transformation of the existing legacy can be divided into several categories: complete retention, repair and reuse, and demolition and reconstruction.

\subsection{Strategies for building public space}

The design of interactive spaces in urban waterfronts greatly enhances the openness and spirit of place of waterfront spaces, the core value of which is the human spirit formed by the interactive tandem with urban spaces. As an important public open space in the city, it is necessary to ensure maximum sharing and diversity of activities, and to design various activity spaces according to people's needs.

The design of interactive spaces in urban waterfronts under the idea of landscape urbanism needs to firstly determine the nature of the surrounding land use and thus the user groups, combine the development characteristics of each section of the waterfront and meet the needs of the user groups in the design of interactive spaces for each function.

\section{Conclusion}

In recent years, the rapid spread of urbanisation has led to increasingly serious environmental problems in urban waterfronts. This paper studies urban waterfronts from the perspective of landscape urbanism, analyses and proposes a landscape planning and design approach for urban waterfronts based on landscape urbanism, in an attempt to change the problems currently faced by urban waterfronts. Through the study and analysis of this theory, this paper hopes to combine it with the landscape design of urban waterfronts and conclude some universal design strategies, which will provide some reference and guidance for the future landscape design of urban waterfronts.

\section{References}

1. Zhang, G.F. (2018) Application of Sponge City Concept in Urban Waterfront Landscape Design. Engineering Construction and Design, 09: 11-12.

2. Zhou, H.G., Shi G. (2018) The application of plant landscaping in modern urban waterfront landscape design-Taking Baipingjiang Xinzhou in Yongzhou as an example. Chinese Urban Forestry, 16(04):75-79.

3. Li, H.L. (2018) Exploration on the planning and design of mountainous rivers to create urban waterfront landscape. Design of Hydropower Station,34(04):73-79+83.

4. Li, M.Y. (2019) Research on Interactive Design of Urban Waterfront Landscape Space.Journal of Fujian Education Institute, 20(01):113-116.

5. Yang, L. (2019) Urban waterfront landscape restoration under the background of "urban double repair". Chinese and Foreign Architecture,08:167168.

6. Zhao, L.B. (2019) Treatment measures for river water environment based on urban landscape design. 
Energy Conservation, 38(08):109-110.

7. Aneta, H. (2019) Architecture as a cultural sustainability factor of Macedonian cities: The branding of Bitola. Sustainable Development,27(2):83-89.

8. Wang, C. (2020) Analysis of landscape optimization in urban waterfront area: Taking the BeijingHangzhou Grand Canal as an example. Heilongjiang Science, 11(22):138-139.

9. Wang, J.Q., Cai, Y. (2021) The application of sponge city in urban waterfront landscape design. Modern Horticulture,44(08):96-97. 